4 Woodrow KM. Gilles de la Tourette's disease-a review. Am $\mathcal{F}$ Psychiatry 1974;131:1000-3.

5 Connell PH, Corbett JA, Horne DJ, Mathews AM. Drug treatment of adolescent tiqueurs. A double-blind trial of diazepam and haloperidol. Br F Psychiatry 1967;113:375-81.

${ }^{6}$ Bruun RD, Shapiro AK, Shapiro E, Sweet R, Wayne H, Solomon GE. A follow-up of 78 patients with Gilles de la Tourette's syndrome. Am $\mathcal{F}$ Psychiatry 1976;133:944-7.

${ }^{7}$ Rosenberger PB, Wheelden JA, Kaltokin M. The effect of haloperidol on stuttering. Am $\mathcal{f}$ Psychiatry 1976;133:331-4.

${ }^{8}$ Davison K. Pharmacological treatment or intractable sneezing. $\mathrm{Br} \mathrm{Medf}$ $1982 ; 284: 1163-40$

${ }^{9}$ Aquilonius S-M, Eckernäs S- $\AA$, Sundwall A. Regional distribution of choline acetyltransferase in the human brain: changes in Huntington's chorea. F Neurol Neurosurg Psychiatry 1975;38:669-77.

${ }^{10}$ Cohen DJ, Shaywitz BA, Joung JG, et al. Central biogenic amine metabolism in children with the syndrome of chronic multiple tics of Gilles de la Tourette: norepinephrine, serotonin, and dopamine. f Am Acad Child Psychiatry 1979;18:320-41.

11 Van Woert MH, Jutkowitz R, Rosenbaum D, Bowers MB. Gilles de la Tourette's syndrome: biochemical approaches. In: Yahr MD, ed. Basal ganglia. New York: Raven Press, 1976:459-65. (Association for Research in Nervous and Mental Disease (ARNMD), Research Publications, vol 55.)

12 Mao CC, Cheney DL, Marco E, Revuelta A, Costa E. Turnover times of gamma-aminobutyric acid and acetylcholine in nucleus caudatus, nucleus accumbens, globus pallidus and substantia nigra: effects of repeated administration of haloperidol. Brain Res 1977;132:375-9.

\section{Pregnancy in the Marfan syndrome}

The Marfan syndrome, an inherited disorder of connective tissue, has a wide geographic and ethnic distribution. The primary features are arachnodactyly, a characteristic habitus because of excessive length of the limbs, and dislocation of the lens. Cardiovascular complications frequently occur, and a substantial proportion of affected people die from aortic incompetence or dissection secondary to progressive changes in the root of the aorta, ${ }^{1}$ the average age of death in a series of 72 patients with the syndrome being $32 .^{2}$

A minimum prevalence of about 1.5 per 100000 has been calculated for Northern Ireland, ${ }^{3}$ and if this figure is valid for other populations there will be at least 750 people with the condition in Britain and around 4000 in the United States.

What advice can be given to a young woman with the Marfan syndrome who is contemplating pregnancy? Can an objective appraisal be made of the risks to the mother and fetus ? Lethal or life-threatening aortic dissection has been reported during pregnancy on several occasions, ${ }^{4-6}$ but these patients may have represented extreme examples; many others are known to have had uneventful pregnancies. Pyeritz has recently reviewed the pregnancies of 26 affected women, ${ }^{7}$ using wives of men with the Marfan syndrome and mothers of sporadic "new mutant" children as controls. He found no differences in the incidence of general complications of pregnancy in these groups, though the spontaneous abortion rate was higher in the women with the Marfan syndrome. Only one of the 26 affected women had evidence of any serious cardiovascular disorder before pregnancy, and she died in the puerperium from endocarditis.

Pyeritz concluded that the risk of death in pregnancy is low in women with the Marfan syndrome who have minimal cardiovascular disease. In contrast, published reports strongly suggest that those with aortic or mitral valvular disease or dilatation of the aortic root are at high risk of potentially lethal complications in pregnancy or during the postnatal period. Pyeritz recommended that a minimum aortic diameter of more than $40 \mathrm{~mm}$, as measured by echocardiographic techniques, or any cardiac decompensation should be taken as contraindications to pregnancy. Conversely, affected women who lack these changes might be advised to proceed with pregnancy under strict obstetric and medical supervision -and they might be urged to complete reproduction early in life before the onset of cardiovascular problems.

The Marfan syndrome is transmitted as an autosomal dominant trait, so any offspring of an affected parent will have an even chance of inheriting the faulty gene and manifesting the disorder. The features in the fetus and newborn are minor, and a child with the condition does not seem to pose any threat to the mother, or vice versa, during pregnancy.

Whether the recognition of the Marfan syndrome in a fetus would justify therapeutic termination of pregnancy is debatable, but prenatal diagnosis by ultrasonography has been attempted in two "at-risk" pregnancies in the second trimester. ${ }^{8}$ In one instance the Marfan syndrome was diagnosed by finding excessive length of the fetal limbs, and after termination typical histological changes were seen in the aorta. In the other pregnancy fetal limb length, as determined by ultrasonography, did not differ from normal, and the pregnancy continued to term. By the age of 21 months some disparity was evident, and the child was thought probably to be affected. On this basis it is evident that, though there is a place for antenatal ultrasonography, definitive diagnosis is not always possible.

Unfortunately diagnosis of the Marfan syndrome may be difficult-both in the adult and in the fetus. In clinical practice several minor examples or formes frustes are encountered for every patient with the full-blown syndrome, and it is often very difficult to know where normality ends and a syndrome begins. To paraphrase McKusick, the greatest problem in the Marfan syndrome is the diagnosis of the disorder in the first place.

Peter Beighton

Professor of Human Genetics,

University of Cape Town Medical School,

Observatory 7925 ,

South Africa

1 Pyeritz RE. Diagnosis and management of cardiovascular disorders in the Marfan syndrome. Fournal of Cardiovascular Medicine 1980;5:759-69.

${ }^{2}$ Murdoch JL, Walker BA, Halpern BL, Kuzma JW, McKusick VA. Life expectancy and causes of death in the Marfan syndrome. N Engl $\mathcal{F}$ Med $1972 ; 286: 804-8$.

3 Lynas MA. Marfan's syndrome in Northern Ireland: an account of thirteen families. Ann Hum Genet 1958;22:289-309.

4 Cava EF, Dreier RL. The Marfan syndrome in pregnancy: a case report. Am F Obstet Gynecol 1971;110:250-4.

5 Elias S, Berkowitz RL. The Marfan syndrome and pregnancy. Obstet Gynecol 1976;47:358-61.

- Rivlin ME. Marfan's syndrome and pregnancy. Fournal of Obstetrics and Gynaecology of the British Commonwealth 1967;74:143-4.

7 Pyeritz RE. Maternal and fetal complications of pregnancy in the Marfan syndrome. $A m \mathcal{F}$ Med $1981 ; 71: 784-90$.

8 Koenigsberg M, Factor S, Cho S, Herskowitz A, Nitoswky H, Morechi R. Fetal Marfan syndrome. Prenatal ultrasound diagnosis with pathological confirmation of skeletal and aortic lesions. Prenatal Diagnosis $1981 ; 1: 241-7$. 